\title{
Estimating the Sea Ice Compressive Strength from Satellite-Derived Sea Ice Drift and NCEP Reanalysis Data*
}

\author{
L.-B. TREMBLAY \\ Lamont-Doherty Earth Observatory, Columbia University, Palisades, New York \\ M. HAKAKIAN \\ Manhasset, New York
}

(Manuscript received 6 October 2004, in final form 17 February 2006)

\begin{abstract}
Satellite-derived sea ice drift maps and sea level pressure from reanalysis data are used to infer upper and lower bounds on the large-scale compressive strength of Arctic sea ice. To this end, the two datasets are searched for special situations in which the wind forcing and its orientation with respect to the coastline allowed the authors to deduce a mean sea ice compressive strength from simple theory. Many estimates of ice compressive strength were possible for the winter of 1992/93 when the Arctic high was confined to the western Arctic and deep penetration of the Icelandic low produced wind patterns that pushed the ice perpendicular to the coastline in the Beaufort and East Siberian Seas. The winter of 1996/97, on the other hand, was characterized by a well-established Arctic high, producing wind patterns that generally pushed ice along coastlines rather than against them. Results show lower and upper bounds on the sea ice compressive strength parameter of 30 and $40 \mathrm{kN} \mathrm{m}^{-2}$, and 35 and $45 \mathrm{kN} \mathrm{m}^{-2}$, for the winters of 1992/93 and 1996/97, respectively (with a potential bias low of about $10 \mathrm{kN} \mathrm{m}^{-2}$ ). A tensile strength for sea ice of about $25 \mathrm{kN}$ $\mathrm{m}^{-2}$ is also found in the East Siberian Sea in the first few hundred kilometers from the land, presumably associated with land-fast ice. The proposed mean ice compressive strength estimate is higher than those derived by minimizing the cumulative error between simulated and observed buoy drift trajectories. It is noted that the uncertainties in the estimates derived from models are large (with an unbiased estimate of standard deviation of $8.75 \mathrm{kN} \mathrm{m}^{-2}$ ). The estimates of yield strength in isotropic compression presented herein are in good agreement with a previous estimate made during the Arctic Ice Dynamic Joint Experiment, and with in situ ice compressive stress measurements made in the Beaufort Sea.
\end{abstract}

\section{Introduction}

The advection of sea ice by surface wind and ocean stresses is a fundamental process affecting the concentration and thickness distribution of sea ice at high latitudes. These two factors in turn control the surface albedo, mediate the heat and freshwater fluxes between the atmosphere and ocean (and between different ocean basins), and through multiple feedbacks have a large influence on the high-latitude climate. For in-

\footnotetext{
* Lamont-Doherty Earth Observatory Contribution Number 6963.
}

Corresponding author address: L.-B. Tremblay, LamontDoherty Earth Observatory, Columbia University, 61 Route 9W, Palisades, NY 10964.

E-mail: tremblay@1deo.columbia.edu stance, projections of future climate change have often shown important changes at high latitudes (Houghton et al. 2001), in part owing to differences in the advection of sea ice. Furthermore, anomalies in sea ice concentrations have been shown to have an effect on the midlatitude climate variability (Parkinson et al. 2001). Thus, an appropriate treatment of the sea ice dynamics in regional and global models is crucial in order to properly account for the effects of sea ice on the highlatitude climate and its variability.

Important controls on the motion of sea ice include the parameters that govern its strength and the rheology that specifies the relationship between the internal ice stresses (induced by winds and ocean currents) and the resulting deformation field. In particular, the stiffness of the pack ice is strongly dependent on its compressive and shear strengths and, to a much smaller extent, on its tensile strength. These parameters set the 
shear and compressive loads required for the ice to fail and start to flow. Their relative magnitude will dictate the proportion of axial and shear strain rates present in the sea ice field (i.e., formation of ridges or flow along slip lines), and also the partition of the energy input from the wind between potential and kinetic energy of the pack and energy dissipated during such deformations. For these reasons, the specification of the sea ice compressive and shear strength parameters will have an influence on the simulated thickness distribution, lead fraction, the motion of sea ice, and ultimately on the amount of sea ice (or freshwater) export out of the Arctic into the northern North Atlantic.

There are two main parameters used to define the compressive strength of sea ice: the yield strength in isotropic compression ( $p^{*}$; Coon et al. 1974) and the compressive strength parameter $\left(P^{*} ;\right.$ Hibler 1979$) .{ }^{1} \mathrm{~A}$ first attempt at independently assessing the yield strength of sea ice in compression was made in the mid-1970s by equating the rate of plastic work done during deformation (i.e., internal stress times strain rate or stretching) to the rate of change of gravitational potential energy and frictional dissipation during the ridging process (Rothrock 1975). The results suggested a yield strength in isotropic compression $p^{*}$ approximately equal to $2 \mathrm{kN} \mathrm{m}^{-1}$ for 2 -m ice thickness. Shortly after, Pritchard (1976, hereinafter referred to as P76) derived a $p^{*}$ value of about $100 \mathrm{kN} \mathrm{m}^{-1}$ for sea ice in the Beaufort Sea using ice drifts and wind measurements from the Arctic Ice Dynamic Joint Experiment (AIDJEX). In this approach, a lower bound on $p^{*}$ was derived by integrating the surface wind stress over the fetch and using the fact that the ice was not deforming under the applied load. Later Pritchard (1981) added a shearing energy sink to the analysis presented by Rothrock (1975), and the resulting ice strength estimate was now in line with that of P76. Direct sea ice stress measurements made on ice floes in the Beaufort Sea show peak values in $\sigma_{2}-\sigma_{1}$ (2 times the maximum shear stress) ranging between 60 and $100 \mathrm{kN} \mathrm{m}^{-2}$ (RichterMenge et al. 2002a,b; Richter-Menge and Elder 1998) in general agreement with P76, assuming that the maximum compressive stress is of the same order of magnitude as the maximum shear stress. More recently, an

\footnotetext{
${ }^{1}$ Here $p^{*}$ is one of three parameters defining the shape of a given yield curve, the other two being the stress invariants $\sigma_{\mathrm{I}}$ and $\sigma_{\mathrm{II}}$, or the principal stresses $\sigma_{1}$ and $\sigma_{2} ; p^{*}$ defines the size of the yield curve but has no effect on its shape. In Hibler (1979), $p^{*}$ and $P^{*}$ are referred to as $P$ and $P^{*}$, respectively. Assuming a linear deformation law, the relationship between the two variables in the standard viscous plastic rheology can be expressed as either $p^{*}=$ $P^{*} h \exp [-C(1-A)]$ or $P=P^{*} h \exp [-C(1-A)]$, where $A$ is the sea ice concentration.
}

indirect assessment of the sea ice compressive strength parameter $\left(P^{*}\right)$ was done by adjusting the value of $P^{*}$ until the error between the simulated and buoy drift trajectories was a minimum. Using this approach, values of 15 (Kreyscher et al. 1997) and 27.5 (Hibler and Walsh 1982) $\mathrm{kN} \mathrm{m}^{-2}$ were obtained for the standard viscous-plastic rheology of Hibler (1979). While the range in model-derived $P^{*}$ is large depending, among other things, on the surface wind stresses used to force the models, these estimates are in general agreement with the value derived from the AIDJEX observations (assuming a typical ice thickness of $3 \mathrm{~m}$ northwest of Banks Islands in February and a linear deformation law).

Recently, the polar remote sensing group of the Jet Propulsion Laboratory (JPL) have compiled almost a decade of satellite-derived winter sea ice drifts for the Arctic, Weddell, and Ross Seas using passive microwave imagery [Special Sensor Microwave Imager (SSM/I)] (Kwok et al. 1998). In the following, satellitederived sea ice drift data and sea level pressure (SLP) from the National Centers for Environmental Prediction (NCEP) reanalysis are used to extend previous estimates of sea ice strength made during AIDJEX. Using this approach, we make a large number of ice strength estimates from which a range of possible values for both $p^{*}$ and $P^{*}$ can be made. The outline of the article is as follows. Section 2 presents the rationale and method used to derive the sea ice strength estimates. In section 3 we presents results for the winters of 1992/93 and 1996/97 for the Arctic Ocean. The main conclusions drawn from this study are summarized in section 4 .

\section{Method}

The methodology used to derive sea ice strength estimates follows that presented in P76. To provide an independent measure of $p^{*}$ and $P^{*}$, as well as additional constraints on the selection of this parameter (i.e., upper and lower bounds), 3-day-averaged sea ice drift velocities from passive microwave satellite imagery and sea level pressure maps $\left(2.5^{\circ} \times 2.5^{\circ}\right.$ spatial resolution and 1-day temporal resolution) from the NCEP reanalysis are analyzed.

\section{a. Upper-bound and lower-bound estimates}

In the Arctic, sea ice drifts on average approximately $5^{\circ}$ to the right of the geostrophic winds in winter (Thorndike and Colony 1982). In the atmospheric boundary layer, the winds turn to the left (because of surface friction). However, the sea ice drift is to the right of the surface wind as a result of the Coriolis 


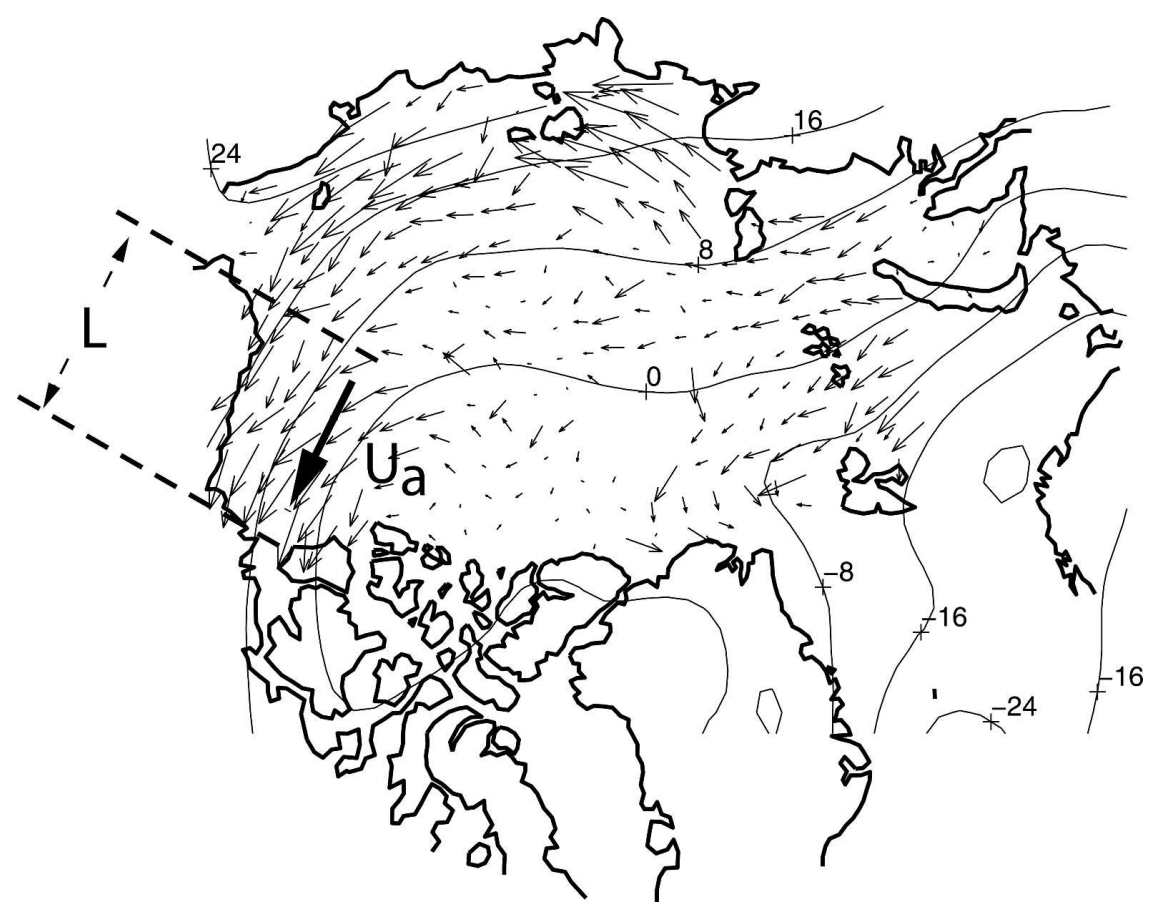

FIG. 1. Example of sea ice drift (arrows) derived from passive microwave imagery from the JPL Polar Remote Sensing Group, and NCEP reanalysis sea level pressure (SLP - $1000 \mathrm{hPa}$ ) for 16 Mar 1993. The fetch $L$ and the geostrophic wind $U_{a}$ are also indicated.

effect. For typical ice thickness, drift speed, and internal ice stresses these two effects almost compensate one another, and the ice flow nearly follows the geostrophic winds and therefore lines of constant sea level pressure [see Fig. 1 or Kwok et al. (1998), their Fig. 2]. Of course, large cross-isobar sea ice flow (to the left or the right) also occurs depending on the relative importance of wind stress, water drag (including wind and water turning angles), the Coriolis effect, and sea ice interaction term (Steele et al. 1997). An example of this is seen in the Laptev Sea, where the sea ice drift is to the right of the isobars (see Fig. 1). In the following, we consider large-scale sea ice motion for which the geostrophic approximation is a good first approximation.

In a first step, instances when the wind blew perpendicular to a coastline for a few consecutive days were identified and recorded. If the ice does not deform under such a condition, the surface wind stress must be balanced by the divergence of the internal ice stress, the water drag, and the sea surface tilt term. Assuming that 1) the geostrophic ocean current is negligible, that is, ocean stress and sea surface tilt terms are ignored (errors associated with this assumption are discussed at the end of this section), and that 2) the forcing is uniform in space $(\partial / \partial y=0)$, the momentum balance in the direction of the flow $(x)$ can be written as (P76)

$$
\tau_{x}=-\frac{\partial \sigma_{x x}}{\partial x},
$$

where $\tau_{x}$ is the wind stress and $\sigma_{x x}$ is the axial component of the sea ice stress tensor acting in the $x$ direction. Integrating over the fetch of the wind $L$ and considering the fact that $\sigma_{x x}$ is always negative, we obtain

$$
-\sigma_{x x}(L)=-\sigma_{x x}(0)+\tau_{x} L>\tau_{x} L .
$$

Since the axial stress is by definition smaller (in magnitude) than the maximum normal stress (expressed in terms of the stress invariant components as $-\sigma_{\mathrm{I}}+\sigma_{\mathrm{II}}$ ), then

$$
-\sigma_{\mathrm{I}}+\sigma_{\mathrm{II}}>\tau_{x} L .
$$

In this equation, $\sigma_{\mathrm{I}}$ and $\sigma_{\mathrm{II}}$ represent the average normal stress and maximum shear stress at a point and can be related to one another for a given choice of yield curve.

For an elliptical (Ell) and a Mohr-Coulomb (MC) yield curve, the relationship between the two stress invariants can be written in normalized coordinates as

$$
\left(\sigma_{I}^{*}+1\right)^{2}+\sigma_{\text {II }}^{* 2} e^{2}=1, \quad \sigma^{*}=\sigma /\left(p^{*} / 2\right): \quad \text { Ell }
$$

and

$$
\sigma_{\text {II }}^{*}+\sigma_{I}^{*} \sin \phi=0, \quad \sigma^{*}=\sigma /\left(p^{*}\right): \quad \mathrm{MC},
$$


where $e$ (the ellipse aspect ratio; Hibler 1979) and $\phi$ (the internal angle of friction; Flato and Hibler 1992; Tremblay and Mysak 1997) give a measure of the sea ice resistance to shear deformation. Using Eqs. (4) and (5), the maximum compressive strength $\left(-\sigma_{\mathrm{I}}+\sigma_{\mathrm{II}}\right)$ can be written as

$$
\begin{aligned}
& \max \left|-\sigma_{\mathrm{I}}^{*}+\sigma_{\mathrm{II}}^{*}\right|=1+\sqrt{1+1 / e^{2}}, \\
& \max \left|-\sigma_{\mathrm{I}}+\sigma_{\mathrm{II}}\right|=\frac{1+\sqrt{1+1 / \mathrm{e}^{2}}}{2} \mathrm{p}^{*}: \text { Ell }
\end{aligned}
$$

and

$$
\begin{aligned}
\max \left|-\sigma_{I}^{*}+\sigma_{I I}^{*}\right| & =1+\sin \phi, \\
\max \left|-\sigma_{\mathrm{I}}+\sigma_{\mathrm{II}}\right| & =(1+\sin \phi) p^{*}: \quad \mathrm{MC} .
\end{aligned}
$$

Note that the maximum compressive strength for the elliptical yield curve is relatively insensitive to the ellipse aspect ratio, ranging from a value of 2.414 for a circular yield curve $(e=1)$ to 2 for the cavitating fluid rheology $(e \rightarrow \infty)$-values quoted are in nondimensional form. For a typical $e$ value of 2, the maximum compressive strength is equal to 2.118. In Eq. (6), the maximum (in magnitude) normal stress occurs at $\sigma_{I}^{*}=$ $\sigma_{\mathrm{I}} /\left(p^{*} / 2\right)=-1-e / \sqrt{1+e^{2}}$. For the Mohr-Coulomb yield curve [Eq. (7)], the maximum normal stress occurs at $\sigma_{\mathrm{I}}^{*}=\sigma_{\mathrm{I}} / p^{*}=-1$.

Combining Eqs. (3), (6), and (7), a lower bound on the compressive strength of sea ice can be expressed as

$p^{*}>\frac{1}{\alpha} \tau_{x} L, \quad$ where $\quad \alpha=\left\{\begin{array}{cc}\left(1+\sqrt{1+1 / e^{2}}\right) / 2: & \text { Ell } \\ 1+\sin \phi: & \text { MC. }\end{array}\right.$

In the above equation, $\tau_{x} L$ represents the total force exerted by the wind over the fetch, and $\alpha$ is a rheologydependent parameter relating the maximum normal stress at a point and the isotropic yield strength of the material in compression. This parameter is expressed as a function of the internal angle of friction $\phi$ for the Mohr-Coulomb yield curve (typically equal to $30^{\circ}$ ) and the ellipse aspect ratio $e$ for the elliptical yield curve (typically equal to 2). In the following, results will be presented for a value of $\alpha=1.0$, representative of the elliptical yield curve ( $\alpha \approx 1.1$ for $e=2)$ and cavitating fluid rheology $(\alpha=1$ for $e \rightarrow \infty)$. For the MohrCoulomb yield curve, $\alpha=1.5$, and the estimates of $p^{*}$ and $P^{*}$ presented later can simply be scaled down by this factor.

In a similar manner, an upper bound on the compressive strength of sea ice is derived for cases when the ice deforms under the applied load. In this case, neglecting the ocean stress (a force retarding the motion of the ice) reverses the sign of the inequality in Eq. (2), so long as the axial stress at the beginning of the fetch $\sigma_{x x}(0)$ is small relative to $\tau_{x} L$. Considering only cases for which the shear stress $\left(\sigma_{x y}\right)$ in the region of interest is small (i.e., $-\sigma_{x x} \approx-\sigma_{y y} \approx \sigma_{\mathrm{I}} \gg \sigma_{\mathrm{II}}$ ), Eq. (3) provides us with an upper bound on the sea ice compressive strength equal to

$$
-\sigma_{\mathrm{I}}+\sigma_{\mathrm{II}} \approx-\sigma_{\mathrm{I}}<\tau_{x} L,
$$

and Eq. (8) still holds with the sign of the inequality reversed. Note that the assumption of small $\sigma_{x x}(0)$ and $\sigma_{x y}$ leads to an error of the same sign on the left-hand and right-hand sides of Eq. (2) that will tend to cancel one another. Using a standard bulk formula (e.g., McPhee 1975), the surface wind stress acting on the ice $\tau_{a}$ can be written as

$$
\tau_{a}=\tau_{x} \mathbf{i}+\tau_{y} \mathbf{j}=\rho_{a} C_{d a}\left|U_{a}\right|^{2}(\cos \theta \mathbf{i}+\sin \theta \mathbf{j}),
$$

where $\rho_{a}\left(=1.3 \mathrm{~kg} \mathrm{~m}^{-3}\right)$ is the air density, $C_{d a}$ $(=0.0012$; Hibler 1979) is the air-ice drag coefficient, $U_{a}$ is the mean geostrophic wind over the fetch $L$ (estimated from the SLP gradient), and $\theta\left(=25^{\circ}\right)$ is the wind turning angle. Assuming a deformation law of the form (Hibler 1979),

$$
p^{*}=P^{*} h,
$$

where $h$ is the thickness of the weakest ice over the fetch $L$, an estimate of the sea ice strength parameter $P^{*}$ can be deduced from the yield strength in isotropic compression $p^{*}$. In the following, we specify $h$ from the seasonal ice thickness climatology of Bourke and Garrett (1987). Sea ice thickness from a high-resolution simulation of the Arctic Ocean forced with contemporaneous atmospheric data (Armstrong et al. 2003) did not lead to any significant differences in the results (not presented here). Ice thickness estimates derived from altimeter measurements in the peripheral seas of the Arctic are starting to emerge (Laxon et al. 2003). When they become available, observed ice thickness can be used to further test this method.

There are several sources of uncertainties associated with this approach. Neglecting the geostrophic ocean current decreases the ice strength estimates by about $15 \%$ (assuming typical values of ocean currents are less than $5 \mathrm{~cm} \mathrm{~s}^{-1}$; P76). Large uncertainties can be associated with the choice of air-ice drag coefficient. Prinsenberg and Peterson (2002) and Smith (1990) report values of $C_{d a}$ over ice surfaces ranging from 0.5 to 5 $\left(\times 10^{-3}\right)$ depending on the atmospheric boundary layer stability and surface roughness. The uncertainty on the mean drag coefficient over large fetches is likely to be much smaller, but results from modeling studies suggest that it may still be large (see discussion in section 3). The geostrophic wind speed derived from NCEP re- 
analysis SLP at high latitude is usually underestimated by about $8 \%$. [This bias, however, is not significant (Cullather and Lynch 2003; Smith et al. 2001; Wylie 2001).] This may translate into an underestimation of the wind stress by about $15 \%$. Errors in wind direction are also present. Francis and Hunter (2005) report 0.5 and $0 \mathrm{~m} \mathrm{~s}^{-1}$ errors in the zonal and meridional components of the surface winds. Given that all events analyzed in this study have a dominant meridional component (perpendicular to a coastline) and assuming a mean wind speed of $5 \mathrm{~m} \mathrm{~s}^{-1}$ in the Beaufort Sea [estimated using data from the Surface Heat Budget of the Arctic (SHEBA) experiment], this gives an error of about $5^{\circ}$ in the wind direction, which amounts to an error of less than $1 \%$ in surface stresses. The measurement of the fetch is relatively precise when compared with other fields. Last, errors of $\pm 50 \mathrm{~cm}$ in sea ice thickness estimates of level ice in the peripheral seas of the Artic were assessed based on the output of a 50-yr sea ice model run by Armstrong et al. (2003). This amounts to approximately $25 \%-40 \%$ of the mean ice thickness for the Beaufort and East Siberian-Laptev Seas, respectively. In October 1997, when the camp for the SHEBA experiment was set up in early winter, sea ice thickness in the Beaufort Sea was approximately $1 \mathrm{~m}$ thinner than expected based on thickness measurements made during the AIDJEX field campaign in the same region in the mid-1970s (McPhee et al. 1998), in general agreement with the model estimates.

In P76, one estimate of sea ice yield strength in isotropic compression was derived from four events that occurred in February 1976 during AIDJEX. In the present study, a large number of estimates of sea ice strength is used to derive ranges of possible values for $p^{*}$ and $P^{*}$. Our large sampling technique minimizes the sensitivity of the results to random errors in wind stress and sea ice thickness. The uncertainty in the final numbers quoted in the next section therefore depends mainly on correlated errors and biases present in those two input fields.

\section{b. Scene identification}

Criteria for selecting sea ice drift events are summarized as follows:

- The wind should be blowing consistently in the same direction and perpendicular to a coastline. The word "consistently" in this context depends on the wind history prior to the events. If the wind was recently blowing sea ice away from the coast, thin ice will be present in the pack, and the first several hours will be used to ridge the newly formed ice in the leads. In this case we require that the wind be blowing consistently for a couple of days before sea ice strength estimates are performed. Again, the spatial and temporal scales associated with the geostrophic winds used in this study are 1 day and of the order of $100 \mathrm{~km}$.

- The wind should be blowing in the same direction over the entire fetch. Large changes in the direction of the winds will induce shear deformation, and the normal load may not be transmitted all of the way to the coastline. Such a case would lead to very low ice strength lower bound estimates, which are not applicable.

The selected events are used to derive strength estimates using sea ice drift data (to determine whether deformation is present) and sea level pressure from NCEP reanalysis (to determine the forcing on the ice).

\section{Results}

Most events used in this study are from the Beaufort, East Siberian, and Laptev Seas. The number of events for the winter of 1992/93 is much larger than for the winter of 1996/97. In 1992/93, the winter was characterized by a deep penetration of low pressure systems into the eastern and central Arctic with a small Arctic high confined to the Beaufort Sea, typical of positive North Atlantic Oscillation (NAO) years in recent decades. This was generally true except sometimes in April and May when the Arctic high occupied the whole Arctic and in late February when low pressure systems entering from the northern North Pacific occupied a large fraction of the Beaufort and Chukchi Seas. During that year the dominant atmospheric circulation pattern was such that sea ice was often blown perpendicular to the coastline in the Beaufort and East Siberian Seas, providing good conditions for ice strength estimates. In 1996/97, on the other hand, the Arctic high often had a col pattern (saddle point) with one lobe over Siberia and another over the Canadian Arctic Archipelago (CAA), or a high occupying the entire central Arctic, as in December and February. These wind patterns often produced very low winds along coastlines or high winds that were more or less parallel to coastlines and thus were less conducive to sea ice strength estimates.

Figures 2, 3, and 4 show the results from the analysis of the daily maps for the winters of 1992/93 and 1996/97. This analysis has provided more than 100 lower and upper bound estimates of the sea ice compressive and tensile strength parameters (for a value of $\alpha=1.0$ ). The estimates are lumped in bins of $5 \mathrm{kN} \mathrm{m}^{-2}$ (or $10 \mathrm{kN} \mathrm{m}^{-1}$ for $p^{*}$ ) ranging from -30 (tensile) to more than 100 (compressive) $\mathrm{kN} \mathrm{m}^{-2}$, and the total number of esti- 

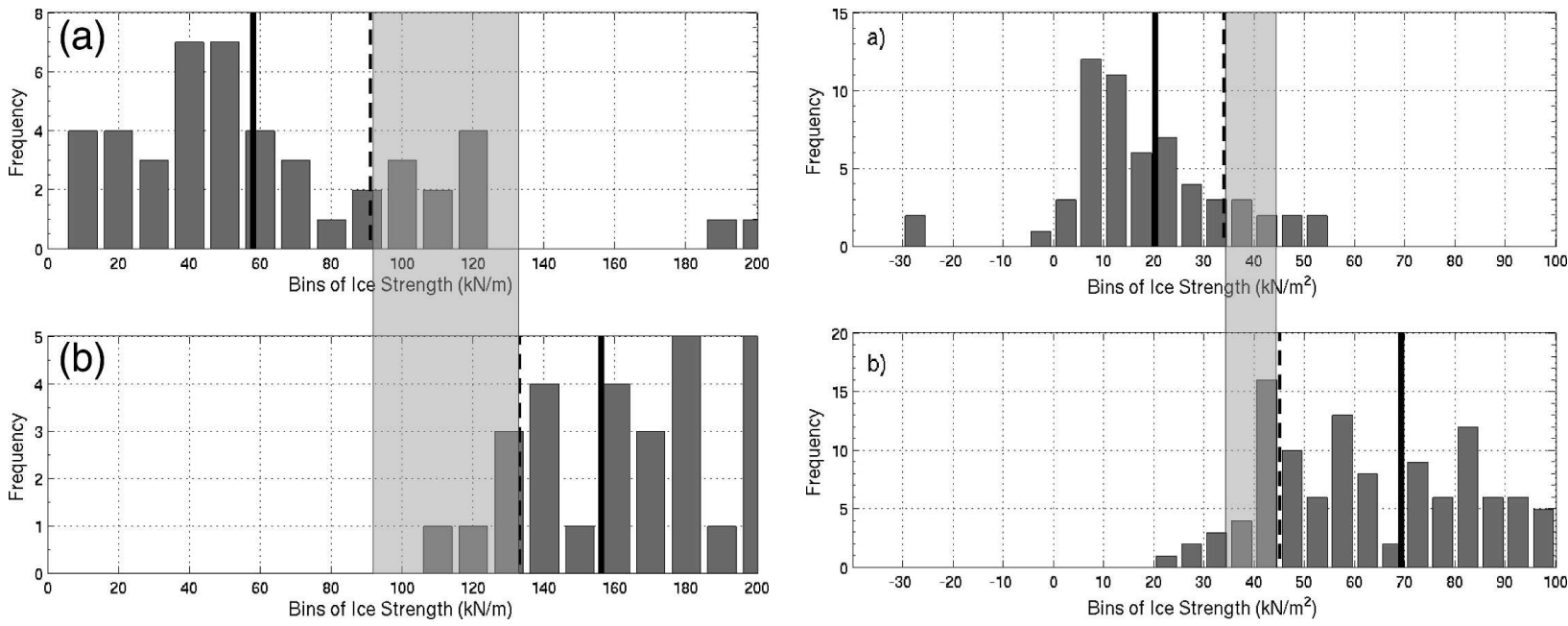

FIG. 2. Histogram of (a) lower-bound and (b) upper-bound estimates of the sea ice yield strength in isotropic compression $\left(p^{*}\right)$ for the Beaufort Sea for JFMA of 1993 and 1997. The thick vertical solid and dashed lines indicate the mean and plus or minus one standard deviation for the $p^{*}$ distributions. The gray shaded area indicates the range of possible yield strength in isotropic compression derived from the upper-bound and lower-bound estimates.

mates in each bin was recorded. In this analysis, upperbound estimates were also included. These were possible because in most cases considered, the ice was pushed against two perpendicular coastlines (e.g., those
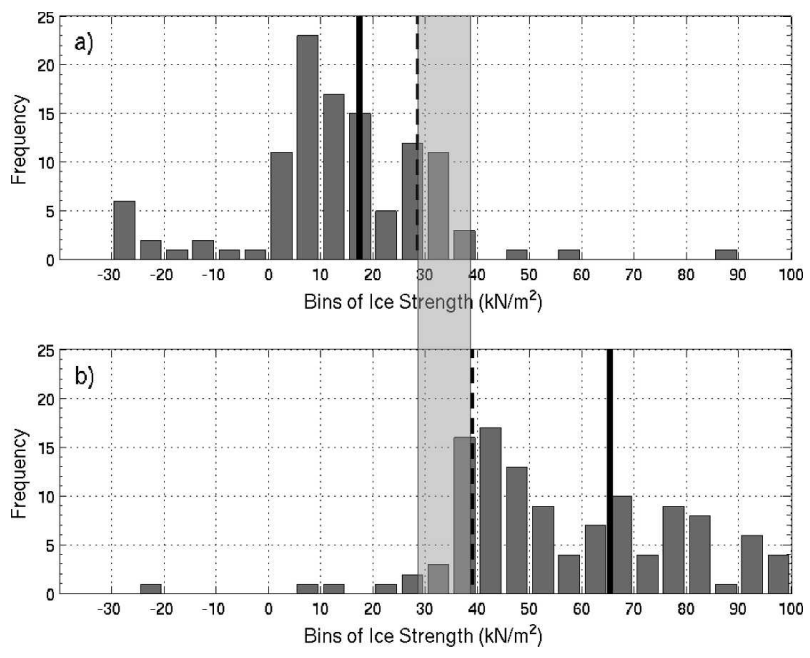

FIG. 3. Histogram of (a) lower-bound and (b) upper-bound estimates of sea ice compressive strength parameter $\left(P^{*}\right)$. These estimates were obtained using satellite-derived sea ice drift data from the winter (October-May) of 1992/93. In (a) tensile strength estimates are shown as negative $P^{*}$. In this case, lower bound refers to the absolute value of $P^{*}$. The thick vertical solid and dashed lines indicate the mean and plus or minus one standard deviation for the $P^{*}$ distributions. The gray-shaded area indicates the range of possible sea ice compressive strength parameter derived from the upper-bound and lower-bound estimates.

FIG. 4. As in Fig. 3 but from the winter (October-May) of 1996/97.

of Banks Island, and the Yukon and Alaskan coastlines); consequently the shear stress within the ice is believed to be relatively small.

The estimates of yield strength in isotropic compression $\left(p^{*}\right)$ for all cases recorded in the Beaufort Sea (when ice was pushed against the Alaskan coast or Banks Island) for peak winter are shown in Fig. 2. The results show a range of possible $p^{*}$ between 90 and 130 $\mathrm{kN} \mathrm{m}{ }^{-1}$, in general agreement with a previous peak winter estimate in the same region made by P76 (100 $\mathrm{kN} \mathrm{m}^{-1}$ ). The estimates of yield strength in isotropic compression are also in general agreement with in situ ice compressive stress measurements made in the Beaufort Sea by Richter-Menge et al. (2002a,b) and RichterMenge and Elder (1998). The range in $p^{*}$ is somewhat large as sea ice of varying thickness is present north of the Alaskan coast and Banks Island. Thicker ice will support larger loads before deformation occurs and will provide larger $p^{*}$ estimates (and vice versa).

Figures 3 and 4 show lower-bound and upper-bound estimates of the compressive strength parameter $\left(P^{*}\right)$. The results for both years are consistent, showing ranges of possible $P^{*}$ values between 30 and $40 \mathrm{kN} \mathrm{m}^{-2}$ for the winter of 1992/93, and 35 and $45 \mathrm{kN} \mathrm{m}^{-2}$ for the winter of 1996/97. Cases in which offshore winds did not cause sea ice deformation were also recorded. These cases were observed mainly in the East Siberian Sea. The results show ice tensile strengths over a couple of hundred kilometers of presumably land-fast ice of about $25-30 \mathrm{kN} \mathrm{m}^{-2}$ (Fig. 3a).

The sensitivity of the sea ice strength estimates to random errors in sea ice thickness [Eq. (10)] is small. To quantify this, the same analysis was repeated using the seasonal ice thickness climatology of Bourke and 
Garrett (1987) $\pm 50 \mathrm{~cm}$ random error (see end of section 2a). This affected the shape of the distributions, but had no noticeable effect on the range of allowable $P^{*}$ presented in Figs. 3 and 4 owing to the large number of events analyzed. Of course, the error may not be random; that is, there could be biases present in one given year. The fact that the analysis of two separate years (1992/93 and 1996/97) with two very different wind patterns in the Arctic give very similar ranges of $P^{*}$ suggests that the uncertainties associated with the choice of ice thickness are comparable to the range quoted for the $P^{*}$ estimates $\left(15 \mathrm{kN} \mathrm{m}^{-2}\right)$. Neglect of ocean currents, however, is believed to lead to a $15 \%$ underestimate of the sea ice strength. The bias low in the NCEP SLP is not significant and therefore is not believed to lead to any significant uncertainty in the range of possible ice strength estimates.

The range of possible $P^{*}$ shown in Figs. 3 and 4 is of the same order of magnitude as previous estimates of $15 \mathrm{kN} \mathrm{m}^{-2}$ by Kreyscher et al. $(1997,2000)$ and $27.5 \mathrm{kN}$ $\mathrm{m}^{-2}$ by Hibler and Walsh (1982). Note, however, the large difference in $P^{*}$ values between the two studies. In both papers, the optimal $P^{*}$ is found by minimizing the error between buoy trajectories and the simulated sea ice drift from the same locations. Kreyscher et al. (2000) use a value of $C_{d a}$ of $2.75 \times 10^{-3}$ and surface winds from the NCEP reanalysis, whereas Hibler and Walsh (1982) uses a $C_{d a}$ of $1.2 \times 10^{-3}$, together with geostrophic wind derived from the NCAR SLP. On average, the NCEP reanalysis surface winds in winter in the Arctic are $10 \%$ smaller than the geostrophic winds in the free troposphere. This leads to $20 \%$ smaller wind stresses, which is not enough to compensate for the large difference in the air-ice drag coefficients used between the two studies $\left[2.75\right.$ versus $\left.1.2\left(\times 10^{-3}\right)\right]$. The disparity is also compounded by the fact that the $P^{*}$ of Kreyscher et al. (2000) is also smaller, despite the larger $C_{d a}$.

Other factors could explain the difference between the two studies, namely, the grid resolution, the buoy data used to minimize the error [the buoy statistics used by Hibler and Walsh (1982) are based on 2 yr of data, whereas those of Kreyscher et al. (2000) are based on $16 \mathrm{yr}$ of data], and the simulated ice thickness [the ice thickness in Hibler and Walsh (1982) is slightly thinner in the central Arctic than that of Kreyscher et al. (2000)]. These differences, however, are not expected to have a large impact on the evaluation of $P^{*}$. Last, both models may not have been iterated until convergence is achieved; for instance, running a model with a smaller pseudo-time step will have an impact on the stress state produced by the model (Zhang and Roth- rock 2000) and the mean kinetic energy of the pack ice (results not shown).

At this point, one thing stands out. The optimal value of $P^{*}$ that should be used in model simulations is intimately linked with the choice of air-ice drag coefficient (i.e., higher energy input from winds and/or higher energy dissipation is required). Uncertainties in the airice drag coefficient are therefore a major source of error in trying to evaluate the appropriate $P^{*}$ to be used in a model study. In our study we calculate the wind stress following Hibler (1979) or Hibler and Walsh (1982), and accordingly our estimates should be compared with the value of $27.5 \mathrm{kN} \mathrm{m}^{-2}$. Taking into account the errors associated with both methods of arriving at $P^{*}$ estimates, we consider the estimate shown in Figs. 3 and 4 to be generally higher than values quoted in the literature. This is reasonable, in part since prior studies use models forced with daily averaged winds (where wind gusts are filtered). To mimic the behavior of real ice, a smaller ice strength in models would be required to compensate for this.

\section{Concluding remarks and future work}

Sea ice drift maps and sea level pressure data from passive microwave imagery and the NCEP reanalysis were used to infer the large-scale compressive strength of sea ice. To this end, we identified instances when the wind was blowing over sea ice perpendicular to a coastline for a few consecutive days during the winters of 1992/93 and 1996/97. Using standard bulk formula, the total force acting on the ice was calculated from the fetch and the mean wind speed acting over that fetch. Results show a possible range of sea ice compressive strengths between 30 and $45 \mathrm{kN} \mathrm{m}^{-2}$, an estimate valid for both elliptical and the cavitating fluid rheologies. For the Mohr-Coulomb yield curve these values are smaller by a factor of 1.5 . The $P^{*}$ estimates are in general agreement but are somewhat larger in magnitude than values derived from the calibration of sea ice models against sea ice drift from buoy data (forced with daily averaged wind). Note, however, that the uncertainty in model-derived $P^{*}$ using this method is large. The range of values for the yield strength in isotropic compression is also in close agreement with a previous estimate made by Pritchard (1976) during AIDJEX in the Beaufort Sea and with in situ stress measurements made in the Beaufort Sea. Future work will include similar estimates for the Southern Ocean, where passive microwave imagery and reanalysis data are also available. Furthermore, as sea ice thicknesses derived from altimeter data are starting to become available, these observations will be used in conjunction with the method presented here to provide $P^{*}$ estimates. 
Acknowledgments. We thank Robert Pritchard for numerous useful discussions and comments during the course of this work, the Jet Propulsion Laboratory for the satellite-derived sea ice drift data (Ron Kwok), the National Centers for Environmental Prediction for the sea level pressure reanalysis data, and Jean-Francois Lemieux for carefully reading the final manuscript and suggesting changes. We are also grateful to Felix Tubiana for his help with the data manipulation and Omar Qureshi for organizing some of the data for the year 1992/93. We also thank one anonymous reviewer and Cathleen Geiger for their careful reviews of the manuscript. Their comments helped to clarify a number of important issues and led to an overall much clearer paper. We thank Katherine Leonard for proofreading the final manuscript. Author B. Tremblay was supported by National Science Foundation Grant OPP9818711.

\section{REFERENCES}

Armstrong, A. E., L.-B. Tremblay, and L. A. Mysak, 2003: A data-model intercomparison study of Arctic sea-ice variability. Climate Dyn., 20, 465-476.

Bourke, R. H., and R. P. Garrett, 1987: Sea ice thickness distribution in the Arctic Ocean. Cold Reg. Sci. Technol., 13, 259280.

Coon, M. D., S. A. Maykut, R. S. Pritchard, D. A. Rothrock, and A. S. Thorndike, 1974: Modelling the pack ice as an elastic plastic material. AIDJEX Bull., 24, 1-105.

Cullather, R. I., and A. H. Lynch, 2003: The annular cycle and interannual variability of atmospheric pressure in the vicinity of the North Pole. Int. J. Climatol., 23, 1161-1183.

Flato, G. M., and W. D. Hibler III, 1992: Modeling pack ice as a cavitating fluid. J. Phys. Oceanogr., 22, 626-651.

Francis, J. A., and E. Hunter, 2005: Arctic tropospheric winds derived from TOVS satellite retrievals. J. Climate, 18, 22702285.

Hibler, W. D., III, 1979: A dynamic thermodynamic sea ice model. J. Phys. Oceanogr., 9, 815-846.

_ _ and J. E. Walsh, 1982: On modeling seasonal and interannual fluctuations of Arctic sea ice. J. Phys. Oceanogr., 12, $1514-1523$

Houghton, J. T., Y. Ding, D. J. Griggs, M. Nouger, P. J. van der Linden, X. Dai, K. Maskell, and C. A. Johnson, Eds., 2001: Climate Change 2001: The Scientific Basis. Cambridge University Press, $881 \mathrm{pp}$.

Kreyscher, M., M. Harder, and P. Lemke, 1997: First results of the Sea-Ice Model Intercomparison Project (SIMIP). Ann. Glaciol., 25, 8-11.

,,-- , and G. M. Flato, 2000: Results of the Sea-Ice Model Intercomparison Project: Evaluation of sea ice rheol- ogy schemes for use in climate simulations. J. Geophys. Res., 105, 11 299-11 320.

Kwok, R., D. A. Schweiger, D. A. Rothrock, S. Pang, and C. Kottmeier, 1998: Assessment of sea ice motion from sequential passive microwave observations with ERS and buoy ice motion. J. Geophys. Res., 103, 8191-8214.

Laxon, S., N. Peacock, and D. Smith, 2003: High interannual variability of sea ice thickness in the Arctic region. Nature, 425, 947-950.

McPhee, M. G., 1975: Ice-ocean momentum transfer for the AIDJEX ice model. AIDJEX Bull., 29, 93-111.

— , T. P. Stanton, J. H. Morison, and D. G. Martinson, 1998: Freshening of the upper ocean in the Arctic: Is perennial sea ice disappearing? Geophys. Res. Lett., 25, 1729-1732.

Parkinson, C. L., D. Rind, R. J. Healy, and D. J. Martinson, 2001: The impact of sea ice concentration accuracies on climate model simulations with the GISS GCM. J. Climate, 14, 2606 2623.

Prinsenberg, S., and I. K. Peterson, 2002: Variations in air-ice drag coefficient due to ice surface roughness. Int. J. Offshore Polar Eng., 12, 121-125.

Pritchard, R., 1981: Mechanical behaviour of pack ice. Mechanics of Structured Media, E. Selvadurai, Ed., Elsevier, 371-405.

Pritchard, R. S., 1976: An estimate of the strength of Arctic pack ice. AIDJEX Bull., 34, 94-113.

Richter-Menge, J. A., and B. Elder, 1998: Characteristics of pack ice stress in the Alaskan Beaufort Sea. J. Geophys. Res., 103, $21817-21829$

$\_,-$, K. Claffey, J. E. Overland, and S. Salo, 2002a: In-situ sea-ice stresses in the Western Arctic during the winter of 2001-2002. Proc. 16th IAHR Int. Symp. on Ice, Dunedin, New Zealand, IAHR, 131-138.

, S. L. McNutt, J. E. Overland, and R. Kwok, 2002b: Relating arctic pack ice stress and deformation under winter conditions. J. Geophys. Res., 107, 8040, doi:10.1029/2000JC000477.

Rothrock, D. A., 1975: Energetics of plastic-deformation of pack ice by ridging. J. Geophys. Res., 80, 4514-4519.

Smith, S. R., D. M. Legler, and K. V. Verzone, 2001: Quantifying undertainties in NCEP reanalysis using high-quality research vessel observations. J. Climate, 14, 4062-4070.

Smith, W. O., 1990: Polar Oceanography. Part A: Physical Science. Academic Press, $406 \mathrm{pp}$.

Steele, M., J. L. Zhang, D. Rothrock, and H. Stern, 1997: The force balance of sea ice in a numerical model of the Arctic ocean. J. Geophys. Res., 102, 21 061-21 072.

Thorndike, A. S., and R. Colony, 1982: Sea ice motion in response to geostrophic winds. J. Geophys. Res., 87, 5845-5852.

Tremblay, L.-B., and L. A. Mysak, 1997: Modelling sea ice as a granular material, including the dilatancy effect. J. Phys. Oceanogr., 27, 2342-2360.

Wylie, D. P., 2001: Arctic weather during the FIRE/ACE flights in 1998. J. Geophys. Res., 106, 15 363-15 375.

Zhang, J., and D. Rothrock, 2000: Modeling Arctic sea ice with an efficient plastic solution. J. Geophys. Res., 105, 3325-3338. 